\title{
Recovery and Then Individual Separation of Platinum, Palladium, and Rhodium from Spent Car Catalytic Converters Using Hydrometallurgical Technique followed by Successive Precipitation Methods
}

\author{
Ahmed M. Yousif $\mathbb{i D}^{1,2}$ \\ ${ }^{1}$ Chemistry Department, College of Science and Arts, Jouf University, Al-Qurayyat, Saudi Arabia \\ ${ }^{2}$ Chemistry Department, Faculty of Science, Menoufia University, Shebin El-Kom, Egypt \\ Correspondence should be addressed to Ahmed M. Yousif; amm_yousif_000@hotmail.com
}

Received 7 July 2019; Revised 7 August 2019; Accepted 30 August 2019; Published 25 September 2019

Academic Editor: Antonio de Lucas-Consuegra

Copyright ( 2019 Ahmed M. Yousif. This is an open access article distributed under the Creative Commons Attribution License, which permits unrestricted use, distribution, and reproduction in any medium, provided the original work is properly cited.

\begin{abstract}
Recovery of PGMs (especially rhodium, platinum, and palladium) from different spent manufactured products (like catalytic converters) is considered as an important task as they are rarely found in nature, and they possess high economic value. In this work, the honeycomb of a car catalytic converter was primarily processed by crushing, grinding, and then treating in a hydrogen atmosphere. In order to establish an economic and ecofriendly method for the recovery of studied PGMs, different experimental conditions of changing $\mathrm{HCl} / \mathrm{H}_{2} \mathrm{O}_{2}$ (as a leaching solution) ratio, temperature, and contact time were studied through batch experiments to obtain the optimum leaching conditions. The use of 0.8 vol $\% \mathrm{H}_{2} \mathrm{O}_{2}$ and $9.0 \mathrm{M} \mathrm{HCl} \mathrm{mixture} \mathrm{at} 60^{\circ} \mathrm{C}$ for a contact time of 2.5 hours during the leaching process may be considered as the best conditions to be followed to save chemicals, energy, and time (about $86 \%, 96 \%$, and $98 \%$ of $\mathrm{Rh}, \mathrm{Pt}$, and $\mathrm{Pd}$ were recovered, respectively). Individual separation of PGM ions from each other using precipitation technique from their leaching liquor was performed where \% purity values of 99.5, 99.3, and 95.5 were obtained for Pt, Pd, and Rh, respectively.
\end{abstract}

\section{Introduction}

In order to reduce the nitrogen oxide, hydrocarbon, and carbon monoxide emissions (they are considered as harmful gases) produced by different vehicle engines, it has been a must for all vehicles produced since 1993 to be fitted with catalytic converters. A catalytic converter contains precious metals (as active components) such as palladium, platinum, and rhodium (referred to as PGMs) in order to convert harmful gases emitted from vehicle engines to relatively harmless ones by both the reduction of nitrogen oxides $\left(\mathrm{NO}_{x}\right)$ into nitrogen $\mathrm{N}_{2}$ and the oxidation of hydrocarbons and $\mathrm{CO}$ to $\mathrm{CO}_{2}[1]$.

Catalytic converters consist of honeycomb skeleton units which possess PGMs on its large surface (as the honeycomb skeleton of each unit increases the contact area between the unit and the vehicle exhaust emissions) [2]. During the manufacturing process, salts of PGMs are impregnated into the surface of honeycomb skeleton using their solutions and then they are reduced to their metallic form [3]. Depending on the manufacturer, the concentrations of PGMs in the unit vary widely. In recent car catalytic converters, Pt concentration ranges from 300 to $1000 \mu \mathrm{g} \cdot \mathrm{g}^{-1}$; for $\mathrm{Pd}$, the concentration ranges from 200 to $800 \mu \mathrm{g} \cdot \mathrm{g}^{-1}$; and for rhodium, they vary from 50 to $120 \mu \mathrm{g} \cdot \mathrm{g}^{-1}$. Therefore, in all cases, the percentage of total content of PGMs in the samples should always be smaller than $0.1 \%$ [4].

Because of the production of PGMs by limited quantities and their high value, there is an increasing demand for their recovery from different spent manufactured products as a secondary source. Besides, from an environmental point of view, such a recovery process should be correctly managed to avoid health and environmental risks $[5,6]$.

Spent catalytic converters are good candidates for such requirement. Several works have been conducted to recover 
PGMs from spent catalytic converters using different metallurgical and refining methods through the use of smelting furnaces, hydrogen pretreatment, and/or direct leaching of PGMs [4, 7-9]. Several leaching processes have been developed based on the selective dissolution of the honeycomb unit consisting of PGMs after its crushing and milling [10]. One of the obstacles faces the dissolution process is the fact that PGMs are inert. Therefore, they are hardly dissolved in ordinary acids. Instead, a mixture of a strong acid (mainly $\mathrm{HCl}$ ) and a suitable strong oxidizing agent (such as nitric acid, chlorate, hypochlorite, perchloric acid, bromated, nitrate, and cupric ions) is required in relatively large amounts to dissolve PGMs during a long period of time estimated in hours [11-13].

Since the leaching processes are usually performed by the use of strong oxidizing agents, their potential effects must be taken into consideration regarding their environmental and safety issues. The use of chlorine compounds requires special care because of their poisoning effect. The use of aqua regia and other $\mathrm{HCl} / \mathrm{HNO}_{3}$ mixtures produces nitrous vapors emission, due to several intermediate and final species generation such as $\mathrm{NOCl}, \mathrm{NO}, \mathrm{NO}_{2}$, and $\mathrm{HNO}_{2}$, besides $\mathrm{Cl}_{2}$ generation, as mentioned elsewhere. The use of cupric ions leaves behind copper compounds in the leaching liquor which are themselves considered as contaminants hardly separated from leached PGMs $[12,14]$. Therefore, these facts lead us to think about the use of efficient and ecofriendly leaching processes.

In the present study, efforts were directed to recover PGMs from processed spent catalytic converters (after pretreatment in a hydrogen atmosphere) using harmless leaching mixtures of hydrochloric acid and hydrogen peroxide as an oxidant (without any harmful gas emission or a residual byproduct generation during the process). Different experimental conditions of changing $\mathrm{HCl} / \mathrm{H}_{2} \mathrm{O}_{2}$ ratio, temperature, and contact time were studied for the leaching processes to obtain the optimum leaching conditions. Other experiments were conducted to individually separate PGMs from each other in the leaching liquor using the precipitation technique.

\section{Experimental}

2.1. Chemicals and Materials. Reagents used in the experiments $\left(36 \% \mathrm{HCl}(12 \mathrm{M})\right.$ and $30 \% \mathrm{H}_{2} \mathrm{O}_{2}$ (w/w) solutions) were Sigma-Aldrich products and used as received. All other chemicals were purchased from Prolabo and Merck and used as received. Double distilled water was used throughout the experimental work. The catalyst used in this study is of honeycomb supports (found in a spent three-way gasoline catalytic converter brought from an end-of-life car management company), which are formed by a cylindrical body traversed by many straight channels and coated with a wash coat on which the PGMs are located.

\subsection{Preparation of the Catalyst Powder and Hydrogen} Pretreatment. The honeycomb unit was crushed and then ground using a cutting mill (IKA MF10) until the powder size reached $0.3 \mathrm{~mm}$. The obtained powder was mixed well (to make it more homogeneous to reduce misleading results during analysis) and then was stored in a desiccator to avoid side reactions. 1 gram of the powder is used in the elemental analysis after digestion with an acid mixture (firstly with $\mathrm{HCl} / \mathrm{HNO}_{3}=3 / 1(\mathrm{v} / \mathrm{v})$ and then $\left.\mathrm{HF}\right)$ in a Teflon vessel at 110 psi relative pressure, using a microwave digester.

Hydrogen pretreatment for obtained powder stabilizes the PGMs in their metallic form in order to be easy to dissolve with the studied leaching mixtures [1]. Accordingly, the powder was treated with a constant hydrogen gas flow $\left(8 \% \mathrm{H}_{2}\right)$ for 20 hours at $100^{\circ} \mathrm{C}$.

2.3. Leaching and Experimental Techniques. Different experimental conditions of $\mathrm{HCl} / \mathrm{H}_{2} \mathrm{O}_{2}$ ratio, contact time, and temperature were studied for the leaching processes to obtain the optimum leaching conditions through the following batch techniques.

For each experiment, solid powder and working leaching solution (solid/solution ratio is $1: 20 \mathrm{w} / \mathrm{v}$, respectively) were put in a $250 \mathrm{~mL}$ flask. The flask was conditioned on a vibromatic shaker at $250 \mathrm{rpm}$ and was immersed in an oil bath at the working temperature and $\mathrm{pH}$ for 3 hours (several preliminary experiments were performed to conclude that the contact time of 3 hours was sufficient for an experiment to reach the optimum leaching capacity). At the end of the experiment, leached PGM ion concentrations in the solution were calculated quantitatively (after clarifying a small portion of the leaching solution through centrifugation) and were compared with the PGM content in the solid powder. Each measurement reading was an average of three replicates.

For monitoring the effect of contact time for the leaching experiment, small portions of the leaching solution were collected throughout the experiment at different time intervals and then centrifuged. Then, the clarified solutions were sent to analysis to record the leaching efficiency as a function of the contact time.

After applying the optimum leaching conditions for a batch experiment, leaching solution containing PGM ions was directed to another treatment to individually separate PGM ions from each other using precipitation technique as illustrated in the following section.

2.4. Individual Separation of PGM Ions from Each Other Using Precipitation Method. This method is based on selecting suitable precipitating agents to be successively added to PGM ions found in their pretreated leaching solution in order to separate them individually as insoluble substances which may be treated after filtration to obtain their pure metallic form as illustrated in the forthcoming section (Section 3.1.).

2.5. Instruments. The elemental analysis, as well as concentration measurements, was performed by using inductively coupled plasma-atomic emission spectrometry (ICP-AES, Horiba Jobin-Yvon Ultima). 


\section{Results and Discussion}

Elemental analysis of $\mathrm{Pd}, \mathrm{Pt}$, and $\mathrm{Rh}$ in the powder is listed in Table 1. The difference in readings for the same metal in the analysis may be attributed to the heterogeneity of samples. Therefore, in all cases, the percentage of total content of PGMs in the samples was found to be smaller than $0.1 \%$ as mentioned in the literature [4].

Conditioning of $\mathrm{HCl} / \mathrm{H}_{2} \mathrm{O}_{2}$ mixture with different compositions to the powder during the batch experiment yields a leaching solution of reddish color. This color is considered as a primary evidence of the existence of PGMs in the powder that they form colored chlorocomplexes as illustrated in the following equations [11]:

$$
\begin{aligned}
\mathrm{Pt}_{(\mathrm{s})}+2 \mathrm{H}_{2} \mathrm{O}_{2(\mathrm{aq})}+6 \mathrm{HCl}_{(\mathrm{aq})} \longleftrightarrow & {\left[\mathrm{PtCl}_{6}\right]^{2-}{ }_{(\mathrm{aq})}+2 \mathrm{H}^{+}{ }_{(\mathrm{aq})} } \\
& +4 \mathrm{H}_{2} \mathrm{O}
\end{aligned}
$$

$$
\begin{aligned}
\mathrm{Pd}_{(\mathrm{s})}+\mathrm{H}_{2} \mathrm{O}_{2(\mathrm{aq})}+4 \mathrm{HCl}_{(\mathrm{aq})} \longleftrightarrow & {\left[\mathrm{PdCl}_{4}\right]^{2-}{ }_{(\mathrm{aq})}+2 \mathrm{H}^{+}{ }_{(\mathrm{aq})} } \\
& +2 \mathrm{H}_{2} \mathrm{O}
\end{aligned}
$$

$$
\begin{aligned}
2 \mathrm{Rh}_{(\mathrm{s})}+3 \mathrm{H}_{2} \mathrm{O}_{2(\mathrm{aq})}+12 \mathrm{HCl}_{(\mathrm{aq})} \longleftrightarrow & 2[\mathrm{RhCl6}]^{3-}{ }_{(\mathrm{aq})} \\
& +6 \mathrm{H}^{+}{ }_{(\mathrm{aq})}+6 \mathrm{H}_{2} \mathrm{O}
\end{aligned}
$$

To study the effect of changing $\mathrm{HCl} / \mathrm{H}_{2} \mathrm{O}_{2}$ ratio on the leaching efficiency, $30 \% \mathrm{H}_{2} \mathrm{O}_{2}$ was added to $12^{\circ} \mathrm{M} \mathrm{HCl}$ of ratios up to $2.4: 100 \mathrm{v} / \mathrm{v}$, respectively, and the leaching efficiencies were recorded through batch experiments and are shown in Figure 1. It is obvious that by increasing $\mathrm{H}_{2} \mathrm{O}_{2} / \mathrm{HCl}$ ratio up to $0.8: 100 \mathrm{v} / \mathrm{v}$, the leaching efficiency increased dramatically. Afterwards, there was no significant increase observed. Gas bubbles were observed after the addition of $\mathrm{H}_{2} \mathrm{O}_{2}$ to the leaching solutions which were considered as a primary evidence of the formation of chlorine gas active species (which react with PGMs to produce their chlorocomplexes in acid solutions) as illustrated in the following equation:

$$
\mathrm{H}_{2} \mathrm{O}_{2(\mathrm{aq})}+2 \mathrm{HCl}_{(\mathrm{aq})} \longleftrightarrow \mathrm{Cl}_{2(\mathrm{~g})}+2 \mathrm{H}_{2} \mathrm{O}
$$

Based on the facts listed above, the following experiments were conditioned by holding 0.8 vol\% $\mathrm{H}_{2} \mathrm{O}_{2}$ as a constant ratio during a series of experiments through which $\mathrm{HCl}$ concentration was varied from 1 to $12 \mathrm{M}$ using distilled water. The obtained leaching efficiencies are shown in Figure 2. As illustrated in the figure, PGM dissolution efficiencies increased dramatically with increasing $\mathrm{HCl}$ concentration till reaching the value of $9.0 \mathrm{M}$. Afterwards, slight increases of the leaching efficiencies were observed. For all experiments, the observed leaching efficiencies order of PGMs was $\mathrm{Pd}>\mathrm{Pt}>\mathrm{Rh}$. By using 11.7 M HCl, the leaching efficiencies of $\mathrm{Pd}, \mathrm{Pt}$, and $\mathrm{Rh}$ were 100,96 , and 88 , respectively.

Figure 3 illustrates the effect of changing the temperature on the leaching efficiencies of PGMs from the powder samples using optimum conditions of $\mathrm{H}_{2} \mathrm{O}_{2}$ volume ratio and $\mathrm{HCl}$
TABle 1: Elemental analysis of Pt, Pd, and Rh of the spent catalyst unit under study.

\begin{tabular}{lccc}
\hline & \multicolumn{3}{c}{ Content $\left(\mu \mathrm{g} \cdot \mathrm{g}^{-1}\right)$} \\
& $\mathrm{Pt}$ & $\mathrm{Pd}$ & $\mathrm{Rh}$ \\
\hline Range & $251-277$ & $391-419$ & $112-126$ \\
Average & 264 & 405 & 119 \\
\hline
\end{tabular}

concentration $\left(0.8\right.$ vol\% $\mathrm{H}_{2} \mathrm{O}_{2}$ and $\left.9.0 \mathrm{M} \mathrm{HCl}\right)$. The temperature was varied in a wide range from $20^{\circ} \mathrm{C}$ to $80^{\circ} \mathrm{C}$. The batch experiments were conducted using well-sealed $250 \mathrm{~mL}$ flasks to avoid evaporation of liquids at high temperatures to maintain the constant solid/solution ratio for all experiments. The results obtained showed that, at all temperatures, the leaching efficiencies followed the order $\mathrm{Pd}>\mathrm{Pt}>\mathrm{Rh}$. For $\mathrm{Pt}$ and Pd curves, the leaching efficiencies increased significantly till reaching a temperature of $60^{\circ} \mathrm{C}$. Afterwards, there was no observable increase in the efficiency values. For Rh curve, the leaching efficiencies increased constantly till reaching a temperature of $60^{\circ} \mathrm{C}$ after which there were no considerable increases in recorded efficiencies.

Figure 4 illustrates the effect of contact time of the batch experiments on the leaching efficiencies of PGMs from the powder sample using optimum conditions of $\mathrm{H}_{2} \mathrm{O}_{2}$ volume ratio, $\mathrm{HCl}$ concentration, and temperature $\left(0.8\right.$ vol\% $\mathrm{H}_{2} \mathrm{O}_{2}$, $9.0 \mathrm{M} \mathrm{HCl}$, and $60^{\circ} \mathrm{C}$ ). The leaching processes possessed high kinetics. Pd and Pt reached equilibrium leaching values after 2 hours, while $\mathrm{Rh}$ reached that value after 2.5 hours. More than the mentioned equilibrium times, leaching time gave no effect to the PGM dissolution.

A comparison between the various variables examined during the leaching experiments is tabulated in Table 2. In terms of an economic feasibility study based on the best conditions that save chemicals, energy, and time, selectively the use of $0.8 \mathrm{vol} \% \mathrm{H}_{2} \mathrm{O}_{2}$ and $9.0 \mathrm{M} \mathrm{HCl}$ mixture in the leaching process at $60^{\circ} \mathrm{C}$ for a contact time of 2.5 hours, respectively may be considered as the best conditions to be followed in the leaching process as about $86 \%, 96 \%$, and $98 \%$ of $\mathrm{Rh}, \mathrm{Pt}$, and $\mathrm{Pd}$ were recovered, respectively.

\subsection{Individual Separation of PGM Ions from Each Other} Using Precipitation Method. A simplified flow sheet of the followed leaching and precipitation techniques is shown in Scheme 1. Primarily, the leaching solution is directed to some treatments before being suitable for individual separation of PGMs from each other. The first step was the distillation of the excess $\mathrm{HCl}$ by evaporation at $190^{\circ} \mathrm{C}$. Then, the dilution of the hot solution with water until a solution of $200 \mathrm{mg} / \mathrm{L}$ Pt was obtained (a suitable precipitation concentration for Pt species) [15]. During dilution, hydrolysis of metal species occurred. The complexes formed remained dissolved in the mother liquor as these species possess high solubility. The hydrolysis probability seemed to be higher for $\mathrm{Pd}$ and $\mathrm{Rh}$ than $\mathrm{Pt}$, which is the reason for their complete separation from $\mathrm{Pt}$ at the precipitation step mentioned in the following section [16]. It is important to say that the distillation temperature must be high enough (not below $190^{\circ} \mathrm{C}$ ) to ensure effective hydrolysis of Pd and Rh species. 


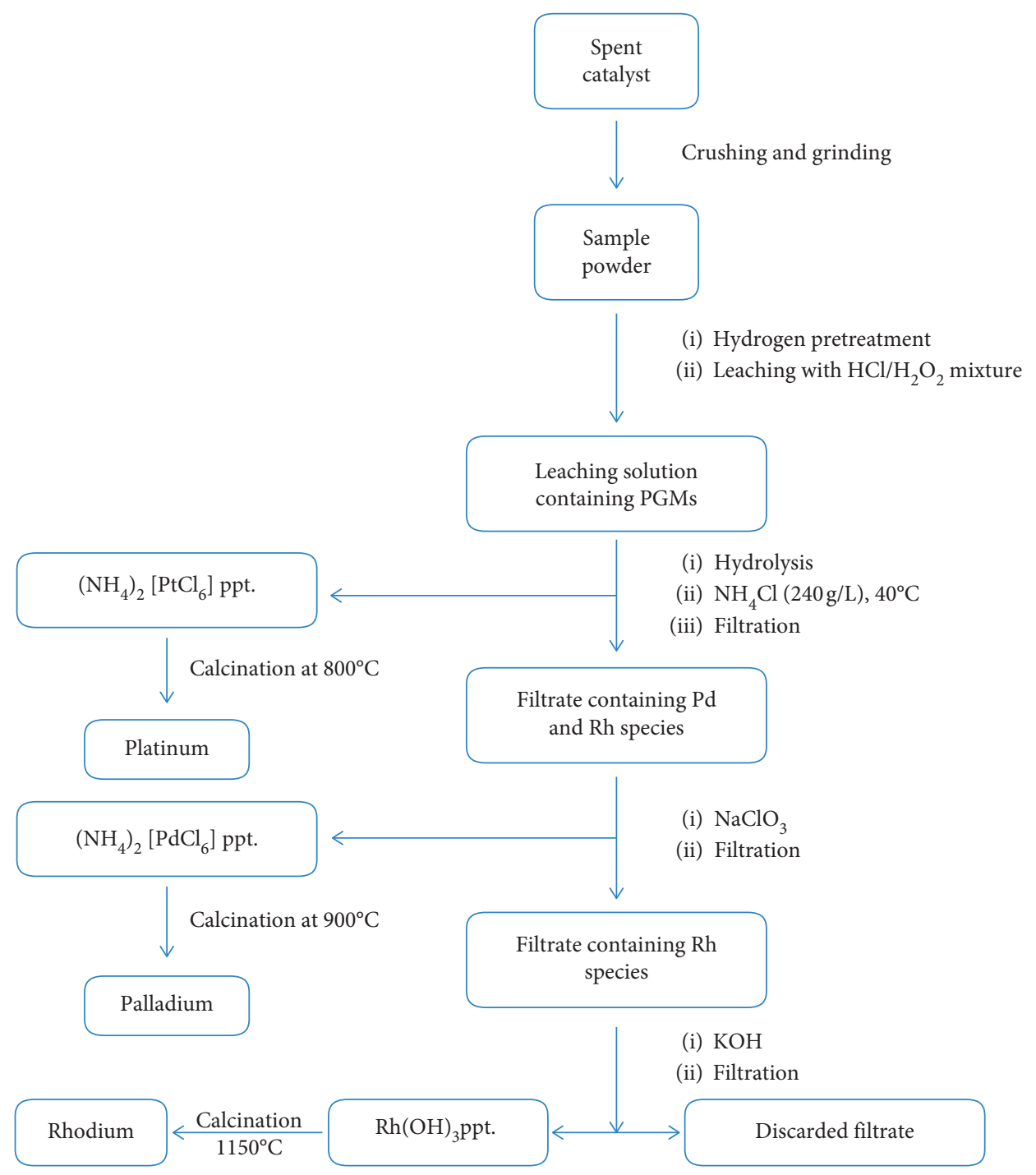

Scheme 1: Simplified flow sheet of the followed leaching and precipitation techniques.

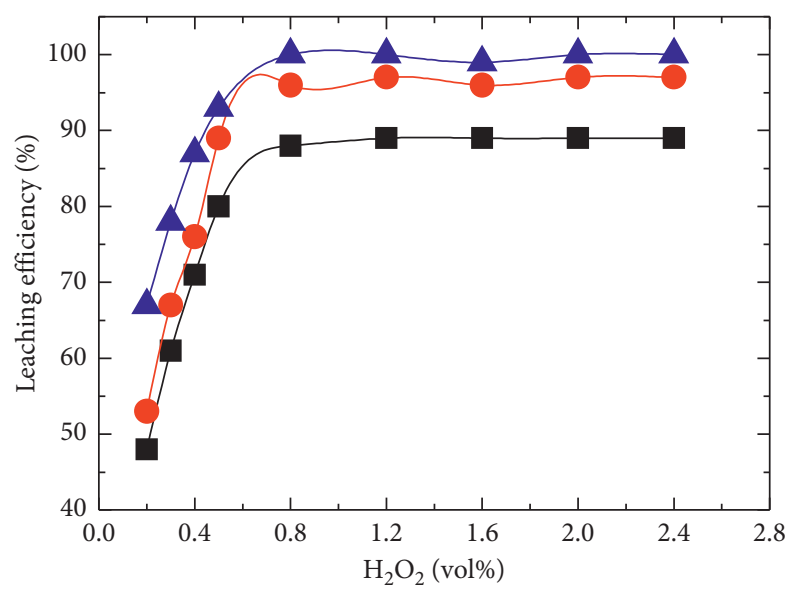

$-\mathrm{Rh}$
$-\mathrm{Pt}$
$-\mathrm{Pd}$

FIGURE 1: Effect of changing $\mathrm{H}_{2} \mathrm{O}_{2} / \mathrm{HCl}$ volume percentage on PGM leaching efficiencies at $60^{\circ} \mathrm{C}$ for 3 hours.

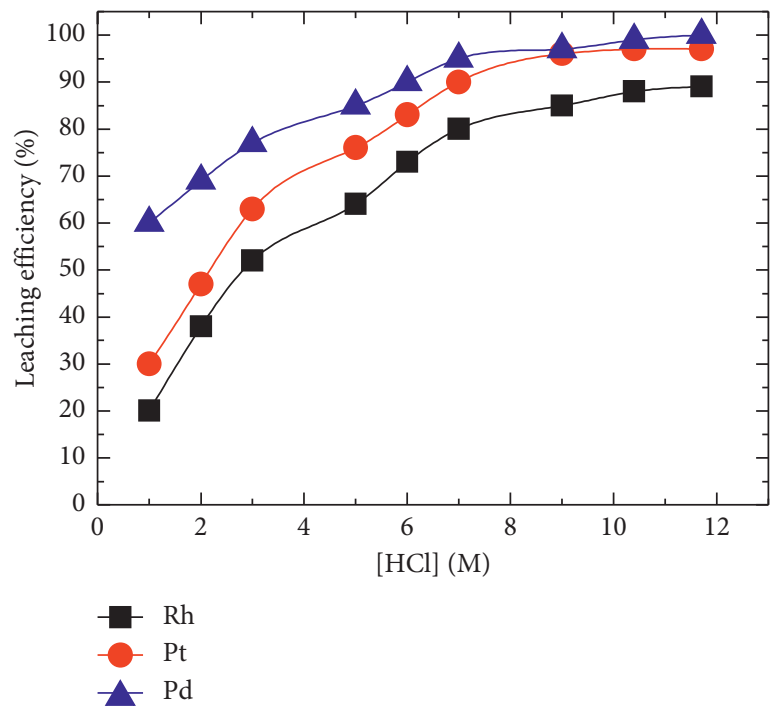

FIGURE 2: Effect of changing $\mathrm{HCl}$ concentration with addition of 0.8 vol\% $\mathrm{H}_{2} \mathrm{O}_{2}$ on PGM leaching efficiencies at $60^{\circ} \mathrm{C}$ for 3 hours. 


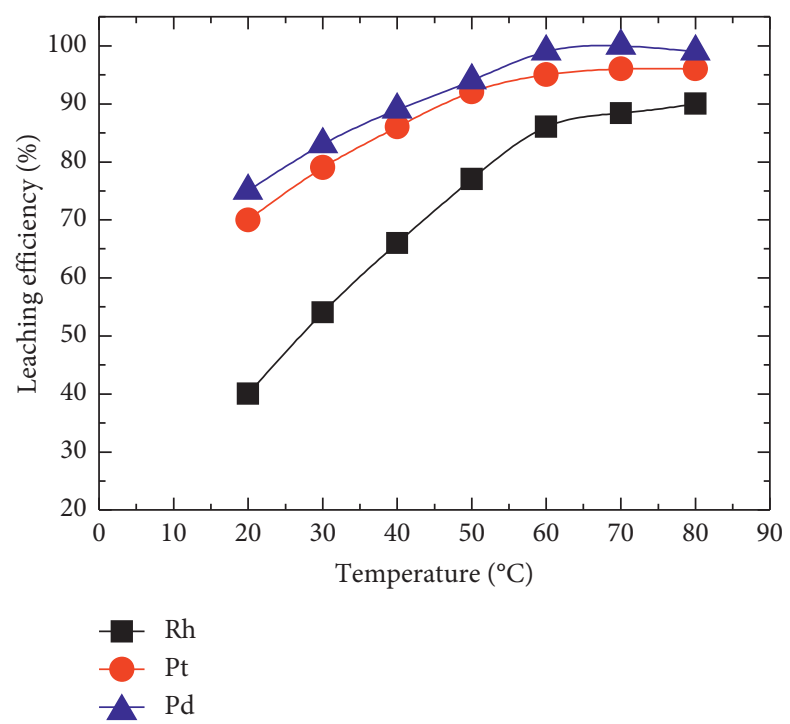

FIGURE 3: Effect of changing temperature on PGM leaching efficiencies using 0.8 vol\% $\mathrm{H}_{2} \mathrm{O}_{2}$ and $9.0 \mathrm{M} \mathrm{HCl}$ for 3 hours.

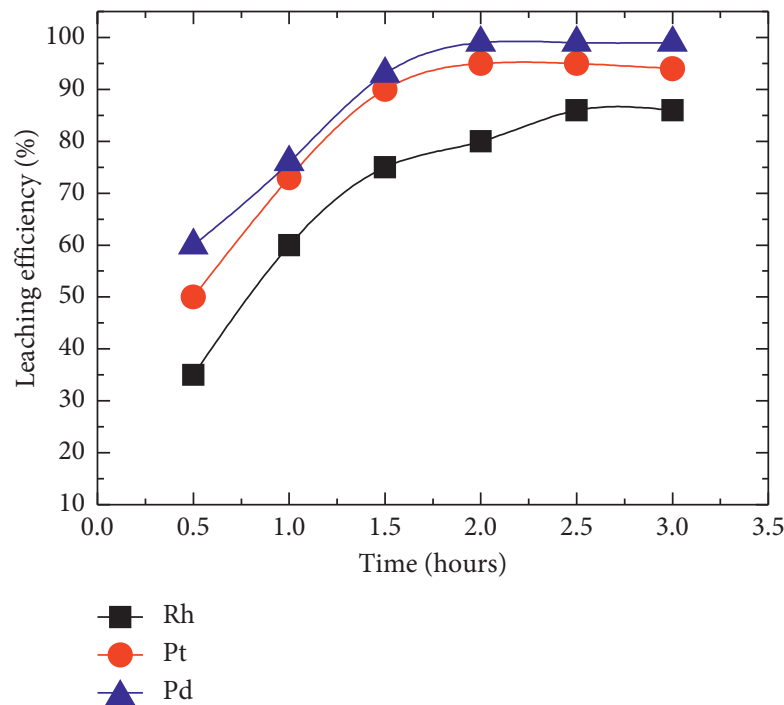

FIGURE 4: Effect of contact time on the PGM leaching efficiencies using 0.8 vol $\% \mathrm{H}_{2} \mathrm{O}_{2}$ and $9.0 \mathrm{M} \mathrm{HCl}$ at $60^{\circ} \mathrm{C}$ for 3 hours.

The individual precipitation of Pt over Pd and Rh from each other was performed by adding $\mathrm{NH}_{4} \mathrm{Cl}(290 \mathrm{~g} / \mathrm{L})$ at $40^{\circ} \mathrm{C}$ to their solution under vigorous stirring. A yellowish $\mathrm{Pt}$ precipitate of $\left(\mathrm{NH}_{4}\right)_{2}\left[\mathrm{PtCl}_{6}\right]$ was obtained. The precipitate was filtered and then washed with a dilute $\mathrm{NH}_{4} \mathrm{Cl}$ solution $(140 \mathrm{~g} / \mathrm{L})$. The filtrate was set aside for later use. The contact time between the mother liquor and the precipitate was kept small to avoid coprecipitation of the impurities with Pt to ensure high purity of the precipitate. Pt precipitate was calcined at $800^{\circ} \mathrm{C}$, washed several times with hot distilled water, and then dried to obtain a fine Pt powder of more than $99.5 \%$ purity. The calcination process may be summarized as follows:

$$
3\left(\mathrm{NH}_{4}\right)_{2}\left[\mathrm{PtCl}_{6}\right] \stackrel{800^{\circ} \mathrm{C}}{\longrightarrow} 3 \mathrm{Pt}_{(\mathrm{s})}+2 \mathrm{NH}_{4} \mathrm{Cl}+16 \mathrm{HCl}+2 \mathrm{~N}_{2}
$$

To precipitate $\mathrm{Pd}$ individually from $\mathrm{Rh}$ found in the filtrate, it was evaporated to concentrate the solution. To the hot solution below boiling temperature was slowly added about 3 grams of sodium chlorate $\left(\mathrm{NaClO}_{3}\right)$ crystals (as they vigorously reacted to the solution due to the presence of organic materials in the solution) with continuous stirring until the bright red precipitate of insoluble $\left(\mathrm{NH}_{4}\right)_{2}\left[\mathrm{PdCl}_{6}\right]$ was completely formed instead of the former soluble form of $\left(\mathrm{NH}_{4}\right)_{2}\left[\mathrm{PdCl}_{4}\right]$. The precipitate was filtered and then washed thoroughly with distilled water, and the filtrate was set aside to extract remaining $\mathrm{Rh}$ as a next step. The dried precipitate was calcined at $900^{\circ} \mathrm{C}$ where a Pd powder of more than $99.3 \%$ purity was obtained and stored in a closed vessel. The calcination process may be illustrated as follows:

$$
3\left(\mathrm{NH}_{4}\right)_{2}\left[\mathrm{PdCl}_{6}\right] \stackrel{900^{\circ} \mathrm{C}}{\longrightarrow} 3 \mathrm{Pd}_{(\mathrm{s})}+2 \mathrm{NH}_{4} \mathrm{Cl}+16 \mathrm{HCl}+2 \mathrm{~N}_{2}
$$

Remaining dissolved rhodium species in the filtrate was precipitated as a lemon yellow rhodium hydroxide 
TABLE 2: Effect of the various variables examined during leaching process on the PGM leaching efficiencies.

\begin{tabular}{|c|c|c|c|c|c|c|}
\hline \multicolumn{4}{|c|}{ Variables studied } & \multicolumn{3}{|c|}{ Leaching efficiency (\%) } \\
\hline Temp. $\left({ }^{\circ} \mathrm{C}\right)$ & $\mathrm{H}_{2} \mathrm{O}_{2}$ (vol\%) & {$[\mathrm{HCl}](\mathrm{M})$} & Time (hours) & $\mathrm{Rh}$ & $\mathrm{Pt}$ & $\mathrm{Pd}$ \\
\hline 60 & 0.2 & 11.92 & 3.0 & 48 & 53 & 67 \\
\hline 60 & 0.3 & 11.88 & 3.0 & 61 & 67 & 78 \\
\hline 60 & 0.4 & 11.84 & 3.0 & 71 & 76 & 87 \\
\hline 60 & 0.5 & 11.80 & 3.0 & 80 & 89 & 93 \\
\hline 60 & $0.8-2.4$ & $11.68-11.36$ & 3.0 & $88-89$ & $96-97$ & 100 \\
\hline 60 & 0.8 & 1.00 & 3.0 & 20 & 30 & 60 \\
\hline 60 & 0.8 & 2.00 & 3.0 & 38 & 47 & 69 \\
\hline 60 & 0.8 & 3.00 & 3.0 & 52 & 63 & 77 \\
\hline 60 & 0.8 & 5.00 & 3.0 & 64 & 76 & 85 \\
\hline 60 & 0.8 & 6.00 & 3.0 & 73 & 83 & 90 \\
\hline 60 & 0.8 & 7.00 & 3.0 & 80 & 90 & 95 \\
\hline 60 & 0.8 & $9.00-11.68$ & 3.0 & $86-88$ & 96 & $98-100$ \\
\hline 20 & 0.8 & 9.00 & 3.0 & 40 & 70 & 75 \\
\hline 30 & 0.8 & 9.00 & 3.0 & 54 & 79 & 83 \\
\hline 40 & 0.8 & 9.00 & 3.0 & 66 & 86 & 89 \\
\hline 50 & 0.8 & 9.00 & 3.0 & 77 & 92 & 94 \\
\hline $60-80$ & 0.8 & 9.00 & 3.0 & $86-90$ & 96 & $98-99$ \\
\hline 60 & 0.8 & 9.00 & 0.5 & 35 & 50 & 60 \\
\hline 60 & 0.8 & 9.00 & 1.0 & 60 & 73 & 76 \\
\hline 60 & 0.8 & 9.00 & 1.5 & 75 & 90 & 93 \\
\hline 60 & 0.8 & 9.00 & 2.0 & 80 & 95 & 98 \\
\hline 60 & 0.8 & 9.00 & $2.5-3.0$ & 86 & 96 & 98 \\
\hline
\end{tabular}

$\left(\mathrm{Rh}(\mathrm{OH})_{3}\right)$ precipitate using $\mathrm{KOH}$ solution by slow addition with stirring until complete precipitation occurred. The precipitate was filtered, washed thoroughly with distilled water, and then dried in air. The complete decomposition in the air for $\mathrm{Rh}(\mathrm{OH})_{3}$ to $\mathrm{Rh}_{2} \mathrm{O}_{3}$ and then $\mathrm{Rh}$ metal was performed by ignition at $1150^{\circ} \mathrm{C}$ to produce a grey $\mathrm{Rh}$ metal powder of $95.4 \%$ purity. Other refining processes may be followed in a forthcoming work (low purity percentage of $\mathrm{Rh}$ may be due to some impurities found in the leaching solution or due to various treatments performed to the individual separation process).

\section{Conclusions}

Selectively, the $\mathrm{HCl} / \mathrm{H}_{2} \mathrm{O}_{2}$ mixture was used as a suitable leaching mixture as it did not cause any harmful gas emission or any residual byproduct generation during the leaching process of PGMs from catalytic converters. Different experimental conditions of changing $\mathrm{HCl} / \mathrm{H}_{2} \mathrm{O}_{2}$ ratio, temperature, and contact time were studied for the leaching processes to obtain the optimum leaching conditions. The use of 0.8 vol\% $\mathrm{H}_{2} \mathrm{O}_{2}$, and $9.0 \mathrm{M} \mathrm{HCl}$ mixture at $60^{\circ} \mathrm{C}$ for a contact time of 2.5 hours during the leaching process may be considered as the best conditions to be followed in order to save chemicals, energy, and time (about 86\%, 96\%, and 98\% of $\mathrm{Rh}, \mathrm{Pt}$, and $\mathrm{Pd}$ were recovered, respectively). $\mathrm{Pt}, \mathrm{Pd}$, and Rh were separated individually from the leaching liquor with $\%$ purity values of 99.5, 99.3, and 95, respectively, by using the precipitation technique.

\section{Data Availability}

The data used to support the findings of this study are included within the article.

\section{Conflicts of Interest}

The authors declare that they have no conflicts of interest.

\section{References}

[1] D. J. de Aberasturi, R. Pinedo, I. R. de Larramendi, J. I. R. de Larramendi, and T. Rojo, "Recovery by hydrometallurgical extraction of the platinum-group metals from car catalytic converters," Minerals Engineering, vol. 24, no. 6, pp. 505-513, 2011.

[2] P. Lucena, J. M. Vadillo, and J. J. Laserna, "Mapping of platinum group metals in automotive exhaust three-way catalysts using laser-induced breakdown spectrometry," $A n$ alytical Chemistry, vol. 71, no. 19, pp. 4385-4391, 1999.

[3] M. Moldovan, M. M. Gómez, and M. A. Palacios, "Determination of platinum, rhodium and palladium in car exhaust fumes," Journal of Analytical Atomic Spectrometry, vol. 14, no. 8, pp. 1163-1169, 1999.

[4] M. Faisal, Y. Atsuta, H. Daimon, and K. Fujie, "Recovery of precious metals from spent automobile catalytic converters using supercritical carbon dioxide," Asia-Pacific Journal of Chemical Engineering, vol. 3, no. 4, pp. 364-367, 2008.

[5] A. M. Yousif, M. Nishioka, Y. Wakui, and T. M. Suzuki, "Adsorption of $\mathrm{Pd}(\mathrm{II}), \mathrm{Pt}(\mathrm{IV})$, and $\mathrm{Rh}(\mathrm{III})$ on a ligand encapsulated polymer resin assisted by thermal heating or microwave irradiation," Solvent Extraction and Ion Exchange, vol. 30, no. 1, pp. 77-87, 2012.

[6] A. M. Yousif, M. Nishioka, Y. Wakui, and T. M. Suzuki, "Rapid adsorption of $\mathrm{Rh}(\mathrm{III})$ by polyamine-functionalized cellulose fiber combined with microwave irradiation," Chemistry Letters, vol. 39, no. 12, pp. 1317-1318, 2010.

[7] Y. Cao, S. Harjanto, A. Shibayama et al., "Kinetic study on the leaching of $\mathrm{Pt}, \mathrm{Pd}$ and $\mathrm{Rh}$ from automotive catalyst residue by using chloride solutions," Materials Transactions, vol. 47, no. 8, pp. 2015-2024, 2006. 
[8] C. Fontàs, V. Salvadó, and M. Hidalgo, "Separation and concentration of $\mathrm{Pd}, \mathrm{Pt}$, and $\mathrm{Rh}$ from automotive catalytic converters by combining two hollow-fiber liquid membrane systems," Industrial and Engineering Chemistry Research, vol. 41, no. 6, pp. 1616-1620, 2002.

[9] C. H. Kim, S. I. Woo, and S. H. Jeon, "Recovery of platinumgroup metals from recycled automotive catalytic converters by carbochlorination," Industrial and Engineering Chemistry Research, vol. 39, no. 5, pp. 1185-1192, 2000.

[10] H. Dong, J. Zhao, J. Chen, Y. Wu, and B. Li, "Recovery of platinum group metals from spent catalysts: a review," International Journal of Mineral Processing, vol. 145, pp. 108113, 2015.

[11] S. Harjanto, Y. Cao, A. Shibayama et al., "Leaching of Pt, Pd and $\mathrm{Rh}$ from automotive catalyst residue in various chloride based solutions," Materials Transactions, vol. 47, no. 1, pp. 129-135, 2006.

[12] M. Massucci, S. L. Clegg, and P. Brimblecombe, "Equilibrium partial pressures, thermodynamic properties of aqueous and solid phases, and $\mathrm{Cl}_{2}$ production from aqueous $\mathrm{HCl}$ and $\mathrm{HNO}_{3}$ and their mixtures," The Journal of Physical Chemistry $A$, vol. 103, no. 21, pp. 4209-4226, 1999.

[13] J. S. Yoo, "Metal recovery and rejuvenation of metal-loaded spent catalysts," Catalysis Today, vol. 44, no. 1-4, pp. 27-46, 1998.

[14] C. A. Nogueira, A. P. Paiva, P. C. Oliveira, M. C. Costa, and A. M. R. da Costa, "Oxidative leaching process with cupric ion in hydrochloric acid media for recovery of Pd and Rh from spent catalytic converters," Journal of Hazardous Materials, vol. 278, pp. 82-90, 2014.

[15] G. Schreier and C. Edtmaier, "Separation of Ir, Pd and Rh from secondary Pt scrap by precipitation and calcination," Hydrometallurgy, vol. 68, no. 1-3, pp. 69-75, 2003.

[16] C. Saguru, S. Ndlovu, and D. Moropeng, "A review of recent studies into hydrometallurgical methods for recovering PGMs from used catalytic converters," Hydrometallurgy, vol. 182, pp. 44-56, 2018. 

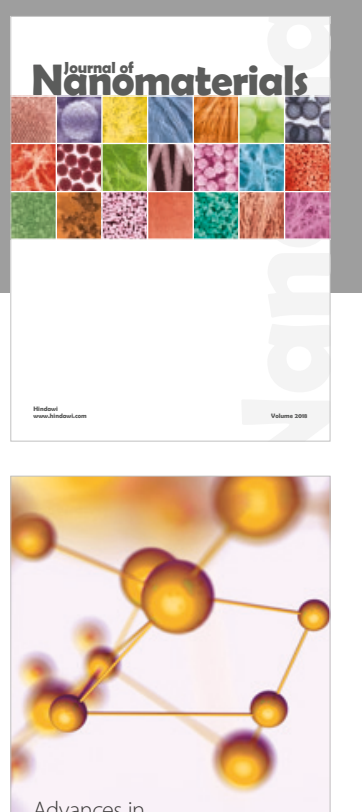

Physical Chemistry
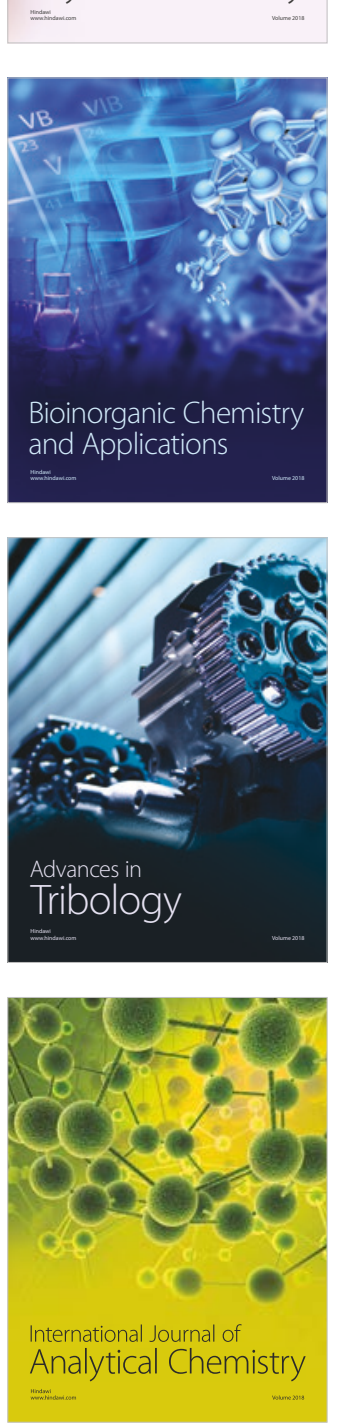

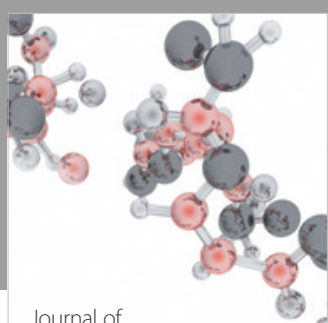

Analytical Methods

in Chemistry

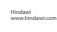

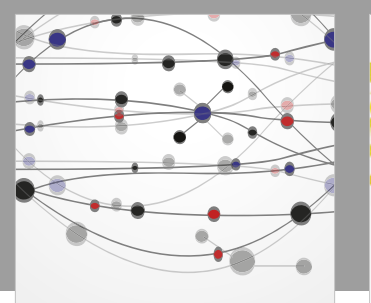

The Scientific World Journal

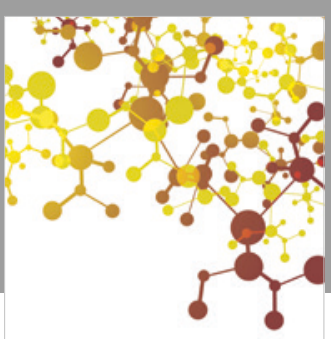

Journal of

Applied Chemistry
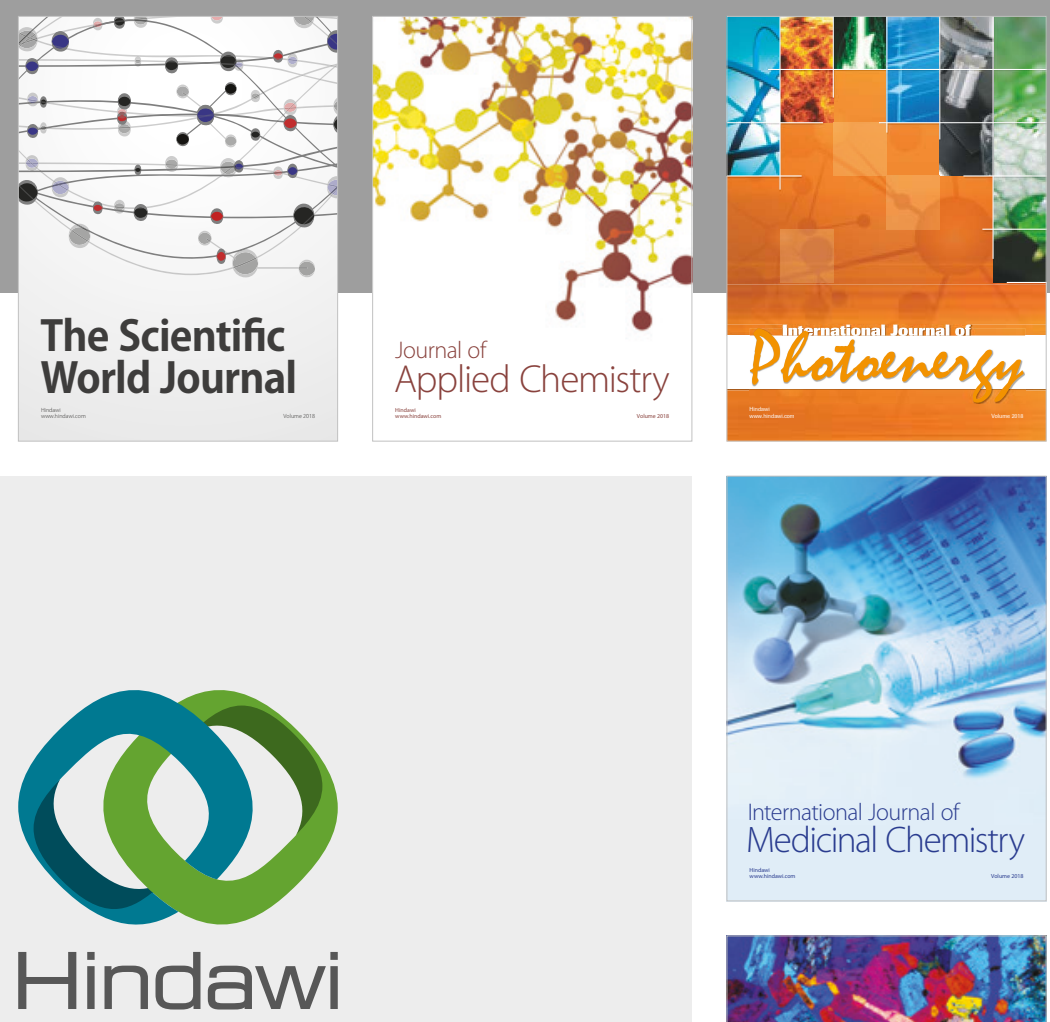

Submit your manuscripts at

www.hindawi.com
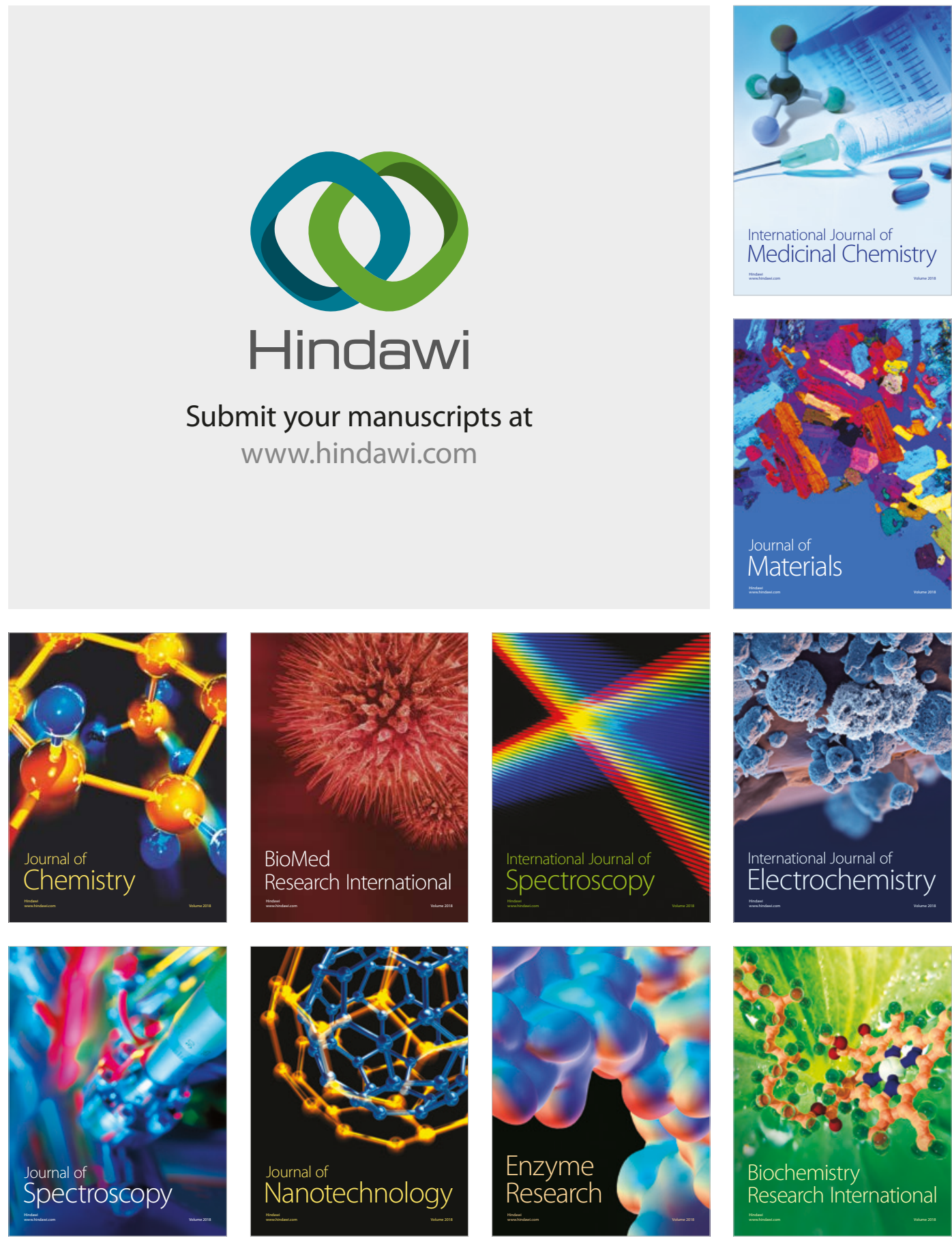
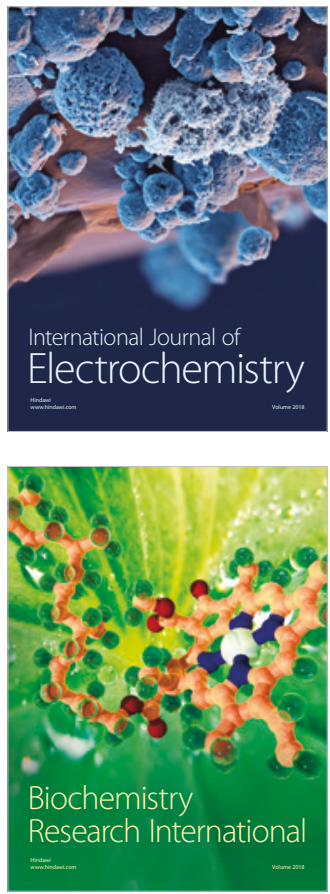